\title{
EXPERIMENTATION WITH MATERIALS TO CREATE CERAMIC PRODUCTS BY MANUAL AND DIGITAL PROCESSES IN A DESIGN WORKSHOP
}

\author{
Cristiane Aun Bertoldi ${ }^{1}$, Barbara del Curto², Denise Dantas ${ }^{3}$ \\ ${ }^{1}$ FAU USP (Brazil) \\ 2 Politecnico di Milano (Italy) \\ ${ }^{3}$ FAU USP (Brazil)
}

\begin{abstract}
In September 2016, a workshop on design and materials was held in São Paulo. It was aimed at design undergraduate students and dealt with the experiments with colours and textures for the creation of ceramic products. This workshop was part of the event Materials and Creation in Design and Architecture: sharing experiences for the creative economy, which was organized through partnership between LabDesign from FAU USP and Materiali e Design, from Politecnico di Milano. This activity belonged to the research project on Materials and innovation for application in the creative industries in the fields of design and architecture: the Politecnico di Milano experience brought to the Brazilian context. The experience of the Italian institution with workshops that involve companies and academia in the development of innovative proposals in design was used as a reference to the planned activities at FAU USP. Grupo Fragnani, a Brazilian ceramic coverings industry was the partner in this entrepreneurship. Their product development team supplied information on their materials and characteristics of the ceramic tile manufacturing processes. The workshop outcomes resulted in the production of ceramic prototypes according to some fabrication parameters given by the company, in relation to the size of the products and the equipment die. Some experiments with different materials were made to provide varied visual and tactile features for the ceramic tiles favoring the students' direct contact with both the clay and its plastic properties and the transformation of the material caused by the firing phase. During the workshop, students developed projects of ceramic tiles with reliefs and textures for application on facades and walls in order to accentuate and value their aesthetic qualities by the incidence of light on the vertical surface. Eighty-five prototypes of tiles of $100 \times 100 \mathrm{~mm}$ with several colours, textures and reliefs were created. Two strategies were used for the creation of the ceramic pieces: digital and manual, both of which were applied for the development of the design and the moulds manufacturing. The students could create relief patterns making use of Photoshop and Rhinoceros softwares, as well as the set-up of the CNC milling equipment. They also created textures and reliefs by pushing and pressing objects against a soft clay surface. Then they developed moulds of plaster of paris from the negative of the surfaces. The visual evaluation of the prototypes showed a huge roll of potentialities for the development of new products by the ceramic industry.
\end{abstract}

Keywords: design, workshop, digital, manual, ceramic.

\section{METHODOLOGY}

This paper presents a methodology to create ceramic products by making use of manual and digital procedures during the design and prototyping phases through the implementation of a workshop on materials and creation in design focused on innovation for the creative economy. The workshop was organised and applied by professors of LabDesign from FAU USP and Materiali e Design from Politecnico di Milano who are members of a research project resulting from an international partnership between these institutions. This paper has been made by means of: a) a general presentation of the workshop methodology and performance $b$ ) a literature review of creativity, materials and design and design education, c) analyses of records of workshop planning and dynamics; c) analyses of images and notes made by professors and researchers, d) evaluation of the educational strategies used in the workshop for design education.

\section{INTRODUCTION: THE WORKSHOP PROPOSAL}

The workshop Design and materials - Experiments with colours and textures for the creation of ceramic products took place from September 5th to 9th, 2016 at FAU USP. Six groups of three undergraduate 
design students took part in this workshop with 24 hours of activities, spread over four days. This event was organized in partnership between LabDesign from FAU USP and Materiali e Design, from Politecnico di Milano. It was part of the event Materials and Creation in Design and Architecture: sharing experiences for the creative economy.

Professors Cristiane Aun Bertoldi, Barbara Del Curto and Denise Dantas were in charge of the organization of the workshop with the support of the monitor Stephani Takahashi. Some didactic materials were prepared, which included two booklets with step-by-step procedures for the development of the design and the prototypes, instructions on the manipulation of materials, as well as the organisation of materials to be used in the creation of new recipes, besides the selection of samples for inspirational experimentations with materials.

This workshop was based on the model used at the Italian institution that brings together companies and academia in the development of innovative proposals in applied research that covers the relationship between the experimentation with materials and the development of projects with the aid of different design methodologies. In the Italian model the partner company presents the briefing, supplies materials and runs the workshop under the supervision of the professor of the Politecnico di Milano, who guides the methods used by students for the phases of experimentation, test and analysis of the results. Some of the outcomes of this kind of workshop have the potential of being used in projects made by professionals of creative economy, namely designers and architects and are expected to be part of a design exhibition. In this scenario, the proximity between the university and the production sector is bound to be encouraged with gains for both sides.

The search for partnerships which involve public universities and companies is not part of the culture of the design courses in the Brazilian reality. The attempt to do that requires a great deal of effort, so some changes had to be made to this workshop. The partner company, Grupo Fragnani, one of the largest ceramic tiles industry in the world, could not afford to provide ceramic materials for the workshop development. However, they presented data on their fabrication processes, raw-material features and parameters for the development of new products in keeping with the dimensional and finishing limits, shown in the samples of products donated. The company also supplied information on its business strategy, focused on production efficiency and low product costs.

The workshop presented by Professor Cristiane Aun Bertoldi of FAU USP was targeted at the development of projects of ceramic tiles for the use on facades and walls, resulting in ceramic prototypes. Design students who participated in the workshop had to deal with different levels of activities and skills. In graphic design disciplines, they are used to working with the development of visual patterns through the application of the concepts of modularity and repetition, making use of different types of symmetry, as well as the continuity of the patterns on the surfaces. What was new to them was the creation of a product design from the direct experimentation with ceramic materials alongside the creation of three-dimensional relief patterns, as will be explained later on. "Fig. 1" shows an overview of the workshop with the simultaneous activities of the manipulation of clay for the generation of reliefs and the preparation of the new clay recipes by the addition of different materials.

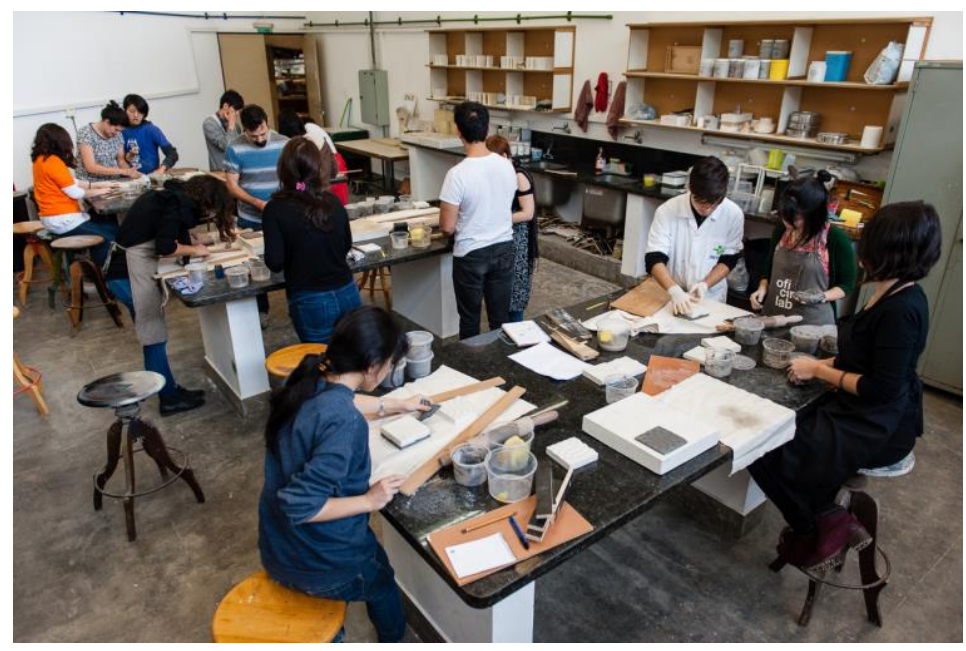

Figure 1. Workshop overview. 


\subsection{Workshop Methodology}

This workshop involved different activities: a) an opening presentation explaining how the workshop would unfold and handing out the timetable; b) a lecture presentation on technical information supplied by the partner company and the description of the methodological procedures based on previous research, c) team formation, distribution of booklets and materials and demonstration of practical operations, d) the creation of clay recipes with varied colours and textures through experimentations with ceramic, organic materials; e) the development of projects of ceramic tiles in a format of $100 \times 100$ $\mathrm{mm}$ and reliefs of 1 to $8 \mathrm{~mm}$ obtained by digital processes; $\mathrm{f}$ ) the development of projects of ceramic tiles in a format of $100 \times 100 \mathrm{~mm}$ and reliefs of 1 to $8 \mathrm{~mm}$ obtained by manual processes; $\mathrm{g}$ ) the development of plaster of paris moulds with reliefs by digital and manual processes, obtaining their positive and negative; $h$ ) forming prototypes by pressing, making use of the created clays; i) finishing the prototypes and encoding them; j) drying and firing the ceramic tiles at $1200{ }^{\circ} \mathrm{C}$; $\mathrm{k}$ ) evaluation of the learning process.

\subsubsection{Opening presentation and the timetable}

During the opening, a presentation was made on the planned activities for the four-day workshop with a detailed timetable as shown in the "Table 1".

Table 1 - Workshop Timetable

\begin{tabular}{|c|c|c|}
\hline & Morning & Afternoon \\
\hline Monday & $\begin{array}{l}\text { Opening } \\
\text { Group formation } \\
\text { Lecture: Grupo Terra Research [1] } \\
\text { Video presentation: Grupo Fragnani production } \\
\text { process } \\
\text { Procedures } \\
\text { Weighing the R04 clay recipe and the materials } \\
\text { to be added (pigments, oxides, fillers) }\end{array}$ & $\begin{array}{l}\text { Preparation of the plaster pieces to be } \\
\text { milled by } \mathrm{CNC} \text { machine } \\
\text { Preparation of } 2 \mathrm{~kg} \text { of } \mathrm{R} 04 \text { clay recipe }\end{array}$ \\
\hline Tuesday & $\begin{array}{l}\text { Demonstration of the digital procedures for the } \\
\text { creation of patterns } \\
\text { Generation of the grey scale image simulating } \\
\text { the relief using the gradient tool in Photoshop } \\
\text { Conversion of the Bitmap image (JPG) into a } \\
\text { NURB surface in Rhinoceros (STL) } \\
\text { Selection of the relief for milling }\end{array}$ & $\begin{array}{l}\text { Milling the plaster pieces by CNC } \\
\text { machine } \\
\text { Addition of pigments, oxides and } \\
\text { fillers to the } 2 \mathrm{~kg} \text { of R04 clay recipe } \\
\text { prepared }\end{array}$ \\
\hline Thursday & $\begin{array}{l}\text { Generation of textures and reliefs in a soft clay } \\
\text { surface by manual procedures } \\
\text { Evaluation and selection of the reliefs } \\
\text { Obtaining the negative of the clay relief in a } \\
\text { plaster of Paris mould } \\
\text { Finishing of the plaster mould }\end{array}$ & $\begin{array}{l}\text { Obtaining the opposite relief of the } \\
\text { plaster of Paris mould } \\
\text { Preparation of the new clay recipes to } \\
\text { be pressed against the moulds }\end{array}$ \\
\hline Friday & Forming the prototypes by pressing & $\begin{array}{l}\text { Encoding the prototypes and finishing } \\
\text { them. } \\
\text { Preparing them to be dried and fired } \\
\text { Conclusion }\end{array}$ \\
\hline
\end{tabular}




\subsubsection{Lecture presentation on technical information and methodological procedures}

Initially, a lecture was given on the procedures for the development of new ceramic materials based on both the methodology and the results of Terra Research Group [1], which covers the creation of colours and textures to produce naked clay recipes for artists and designers in their ceramic works. A video of Fragnani Group company, partner in this activity, could equip students with information on production processes and product parameters for the design development of tiles. "Fig. 2" shows the lecture and the video provided the liminal and necessary technical knowledge to carry out the workshop tasks.
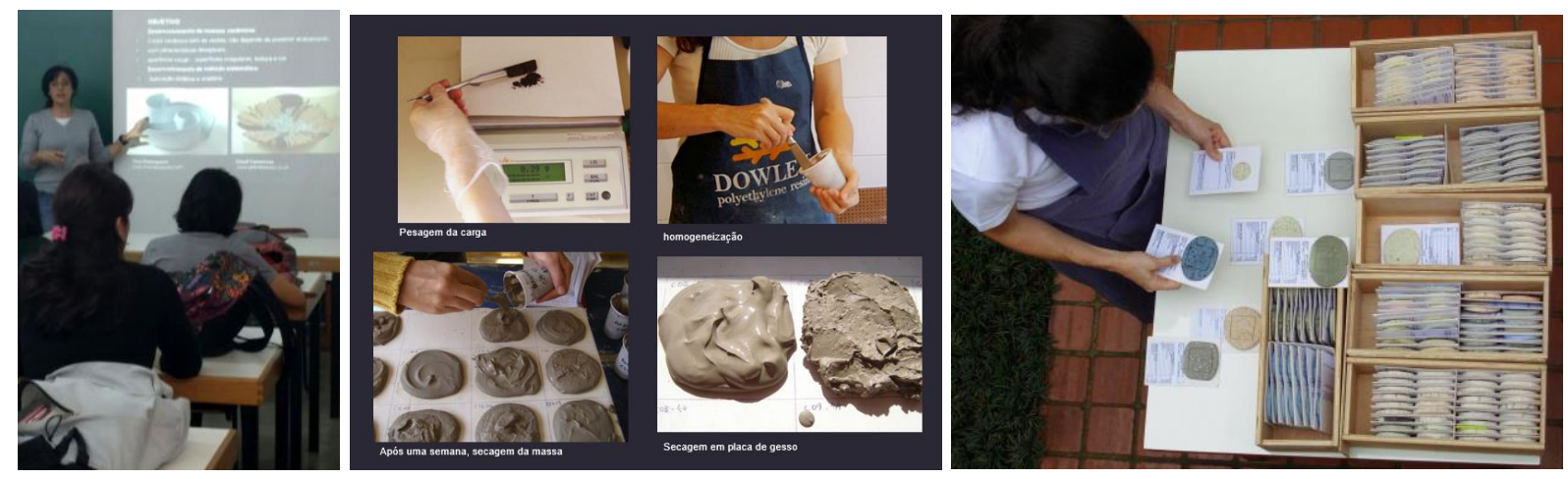

Figure 2. Lecture on the procedures for the development of new ceramic materials based on both the methodology and the results of Terra Research Group.

\subsubsection{Team formation, distribution of booklets and materials, demonstration of practical operations}

Teams of three students received didactic support material with relevant information on the development of the activities during the four days of the workshop. One booklet presented the procedures for the generation of two-dimensional images in grayscale and its conversion into three-dimensional reliefs with the support of two computer programs. Another booklet illustrated the step-by-step of the actions for the creation of new clay recipes from the addition of varied materials in specified quantities, the work with plaster to make moulds for pressing, the procedures of the preparation of ceramic clay, the pressing of pieces and their encoding "Fig. 3". The activities in the workshop were initiated after a practical demonstration of the operations of material mixing, preparation of the clay and conformation of parts.

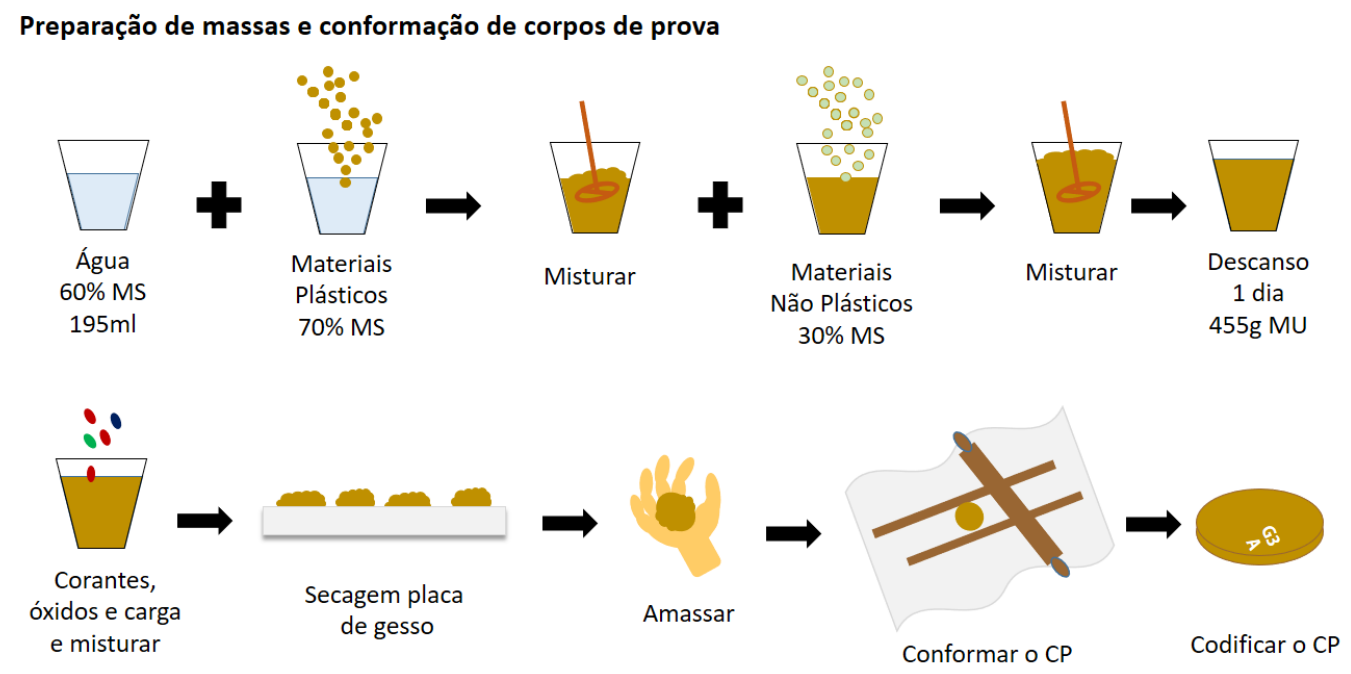

Figure 3. Illustration in the booklet showing the step-by-step of the procedures of the preparation of ceramic clay, the pressing of the pieces and their encoding.

\subsubsection{Development of new ceramic recipes fired at $1200^{\circ} \mathrm{C}$ with varied colours and textures.}

The new materials were created from the use of the R04 clay recipe, developed by the Terra research group (Grinberg et tal 2008). The raw materials presented in the R04 clay recipe and their percentages are: $30 \%$ ball clay, $40 \%$ clay, $10 \%$ potassium feldspar, $12 \%$ sodium feldspar, $5 \%$ quartz and $3 \%$ talc. 
This ceramic material is fired at $1200^{\circ} \mathrm{C}$ in an electric kiln. The comparison among the samples of the 184 ceramic materials created by the Terra Research group served as reference for the development of new ceramic materials during the workshop as well as the observation of the behaviour of the raw materials after they had been fired at $1200^{\circ} \mathrm{C}$ "Fig 4". The colour and the texture of each ceramic material were observed and the visual and tactile qualities were considered for the selection of the samples by the students.
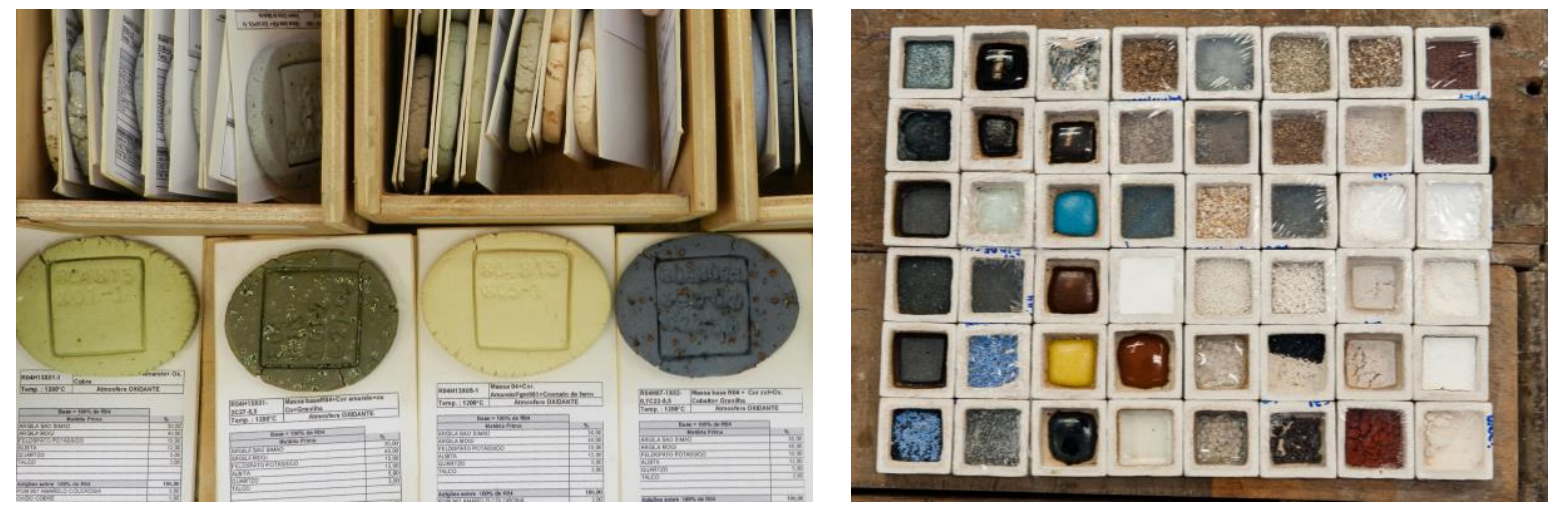

Figure 4. Selected samples of clay recipes developed by Terra Research Group and raw materials behaviour after they had been fired at $1200^{\circ} \mathrm{C}$.

After selecting samples of ceramic materials those recipes were used as parameters for new formulations, concerning the percentages of pigments, oxides and fillers added to the R04 clay - "Fig 5". The preparation of the new clay recipes was based on the use of $20 \mathrm{~kg}$ of R04 clay with $60 \%$ of water to obtain a creamy consistency to facilitate the mixing with other materials.
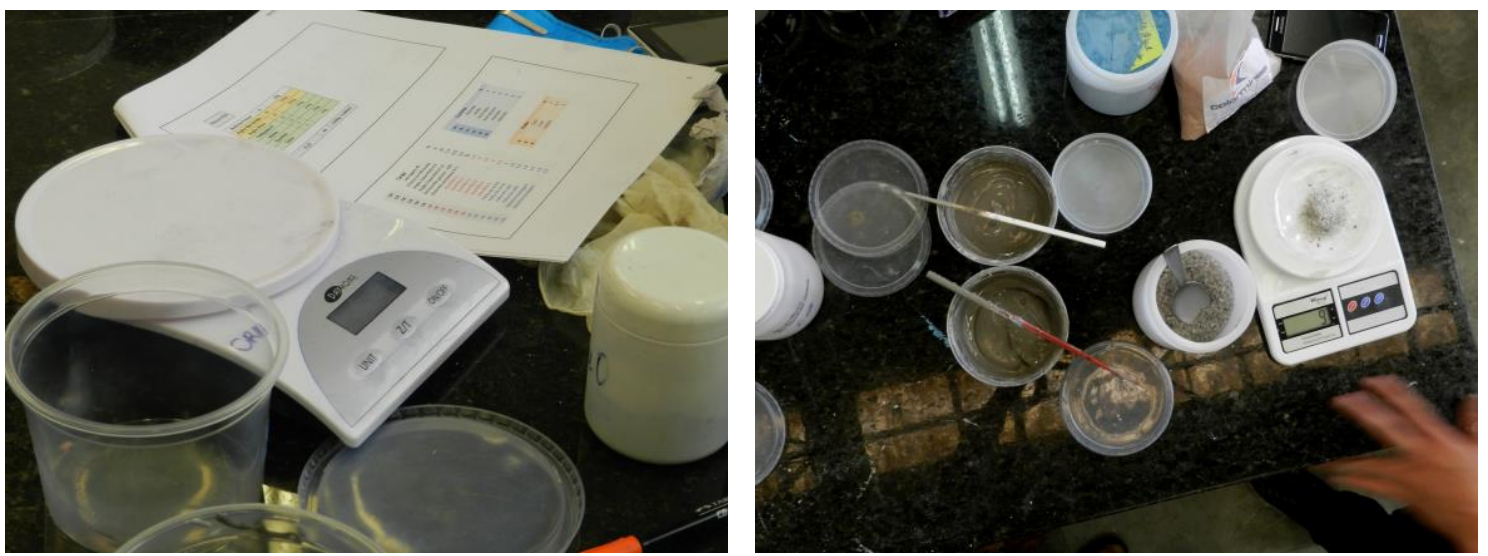

Figure 5. New recipes developed by students, based on the outcome of Terra Research Group

\subsubsection{Development of press moulds with reliefs for $10 \times 10 \mathrm{~cm}$ tiles}

As mentioned earlier, the parameters provided by the partner company in this workshop, the Fragnani Group, served as a basis for the development of the projects. The dimensions of $10 \times 10 \mathrm{~cm}$ correspond to the size of the smallest pieces produced in the factory. Likewise, the relief of up to $8 \mathrm{~mm}$ refers to the limits achieved in the pressing of the products. Knowing that the behaviour of the ceramic recipe R04 that presents $10.8 \%$ retraction after being fired, the students were advised to plan the development of pattern design and moulds with a magnification of 1.12 to result in prototypes with sizes of the reference company's products. The projects under development refer to tiles for application on facades and walls. The incidence of light on the vertical surface makes the most subtle reliefs and textures visible. The design of tiles presupposes the occupation of continuous surfaces, so it was necessary to provide some information and tips on how to create patterns for repetition and filling of continuous surfaces and to stimulate the creativity for their creation.

The creation of the moulds involved two procedures: digital process and manual process. The creation of the design patterns considered the possibility of articulating modules of $11.2 \times 11.2 \mathrm{~cm}$ in symmetries of translation, mirroring, rotation, with the aim of obtaining continuous and integrated surfaces. In the same way, the students experimented on the development of the design by making use of digital and 
manual processes. For the creation of plaster of paris moulds in digital processes, pieces of $11.2 \times 11.2$ $x 2 \mathrm{~cm}$ of this material had been made beforehand to be milled.

Two computer programs were used In the digital process for the creation of the reliefs of the tiles design: Photoshop and Rhinoceros. With Photoshop, patterns in $11.2 \times 11.2 \mathrm{~cm}$ formats were created through bi-dimensional images in greyscale using the gradient tool because it favours a smooth transition between light and dark. Then a BITMAP image in JPG files were obtained "Fig 6". Simulations of the repetitions of the modules were made to create continuous surfaces (rapport) and these operations helped to choose the best alternatives of images to be transformed into reliefs. Using the Rhinoceros program, by selecting from the Surface menu and the Heightfield from Image command, it was possible to capture a BITMAP image in JPG file that had been created in Photoshop and convert the 2D image into a 3D relief, saved in a STL format.

The visualization of the reliefs obtained in the Rhinoceros program using a rendered view presentation allowed for the evaluation of the results achieved in the digital simulation. The program interprets the dark and the light colours considering the lower part of the relief as black and the upper part as white. The several shades of grey lie on the intermediate levels. Therefore, when an image presents a subtle gradient from black to white, the relief is also smooth, with a soft transition between the upper and the lower parts. On the other hand, when an image presents a sharp contrast between black and white, the relief shows a markedly uneven form. After the creation and the visualization of the relief the project is either accepted or discarded. Until the project is approved a back-and-forth operation occurs, from the creation of 2D images to 3D reliefs. The approved STL file, generated in Rhinoceros after the simulation, was used in the machining of the plaster moulds using a 3-axis CNC milling machine "Fig 7".
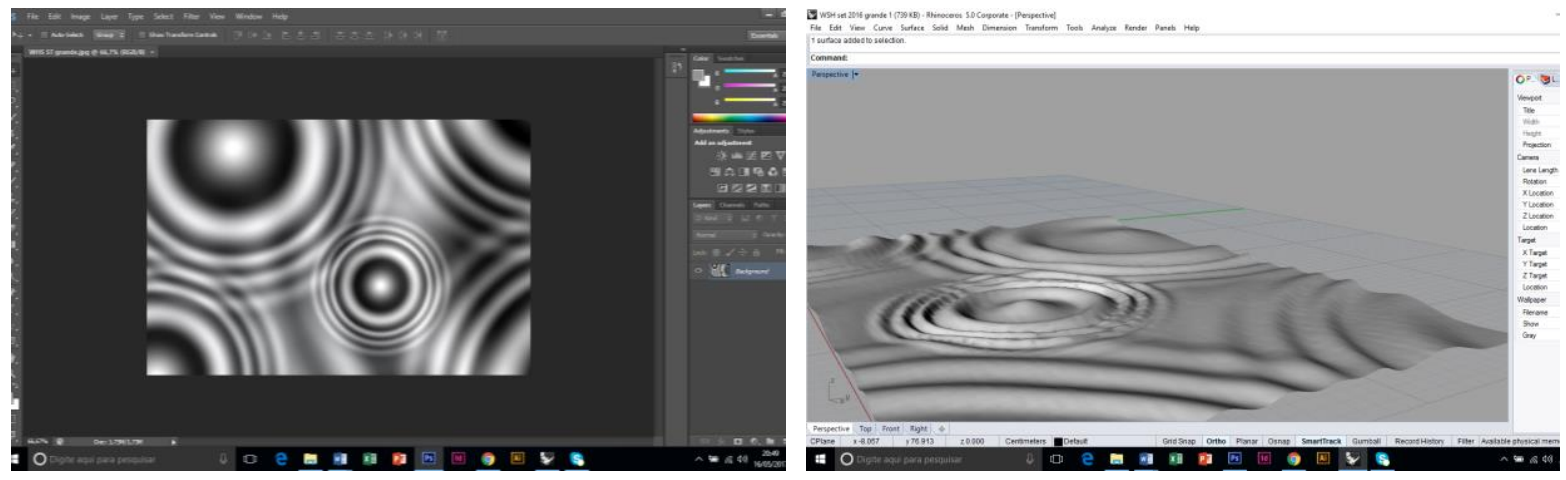

Figure 6. Photoshop 2-D grey scale image created and the 3-D converted relief in Rhinoceros.
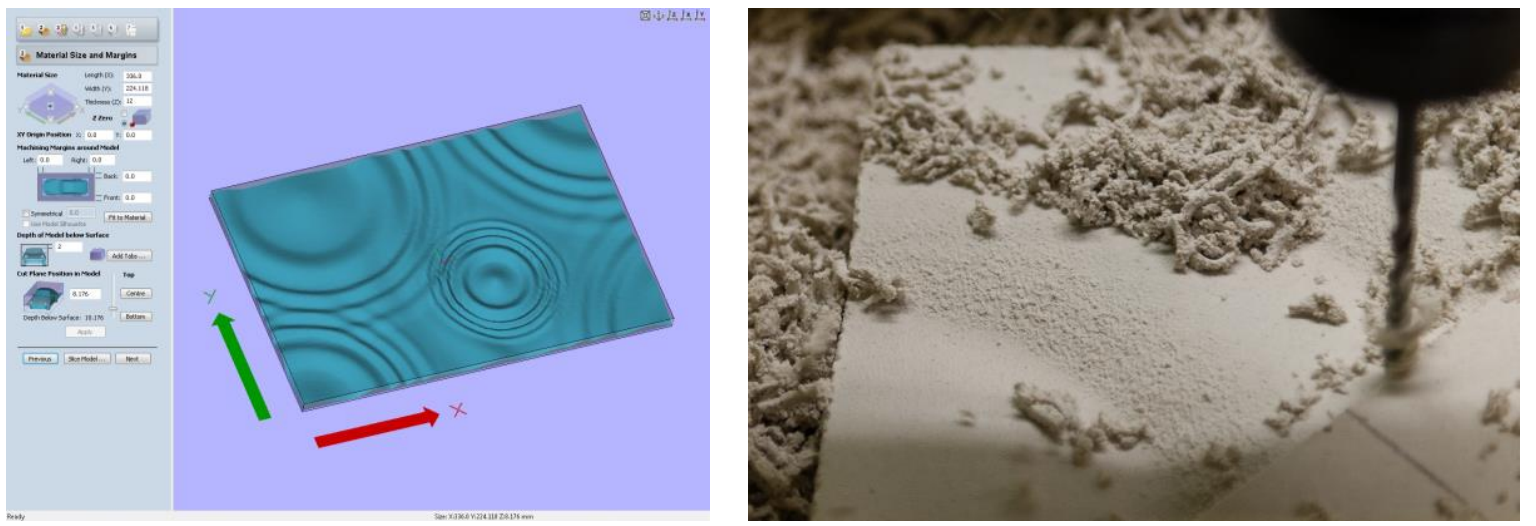

Figure 7. Setting up the CAM equipment and machining of the plaster moulds using a 3-axis CNC milling machine.

For the development of reliefs through manual processes the plasticity of the clay was explored. The ease of working, altering and correcting the clay makes it a perfect material to generate alternatives in the design process, such as sketches on paper. To produce the reliefs, a few slabs of $11.2 \times 11.2 \times 0.9$ $\mathrm{cm}$ of plastic clay were made, with the aid of a rolling pin and two wooden guides to keep up a uniform thickness. Against the soft clay surface, different objects were pushed and pressed in order to create varied patterns, from subtle to incisive ones. All the pressing and pushing done to the clay surface create textures and reliefs where their tactile and / or visual character is accentuated, some of which being really unexpected and interesting, and it can be seen on the "Fig. 8". 

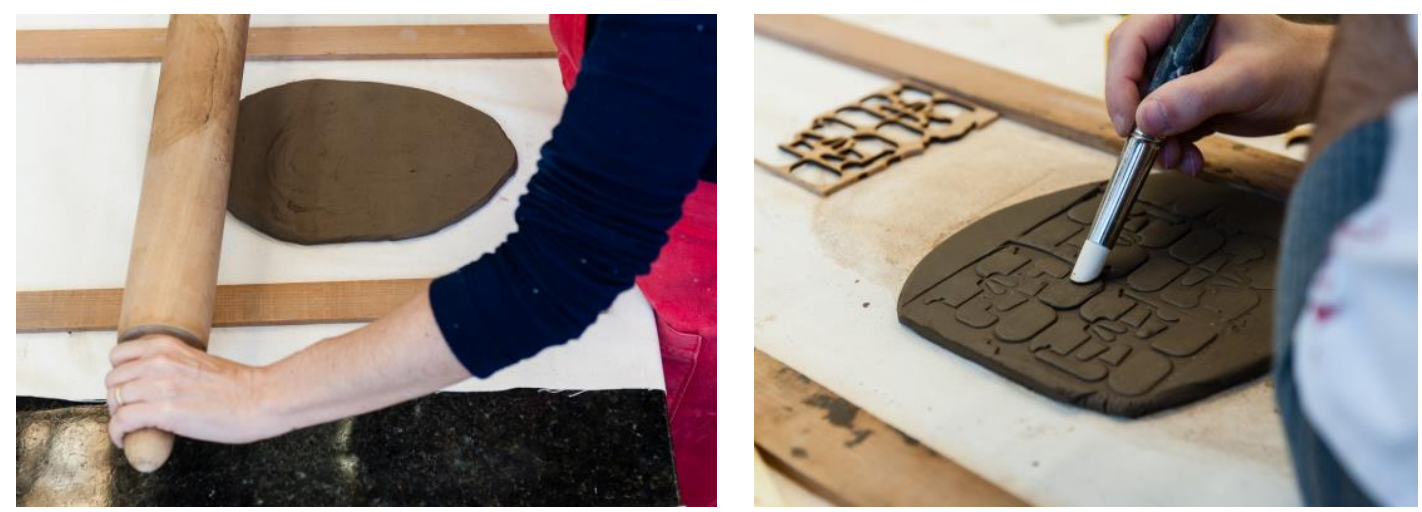

Figure 8. Two images showing the slab forming and the pushing and pressing of different objects against the clay surface.

Visual comparisons among varied reliefs help the students to select the best alternatives for the creation of the plaster of paris moulds. To do so, wooden walls were put up around the pieces with the chosen patterns. Then plaster was prepared with water and poured over the pieces of clay with the reliefs because it is capable of filling and delimiting each created shaft. After a few minutes, the plaster moulds show the negatives of the reliefs and reveals interesting images that can be used in the project "Fig 9".
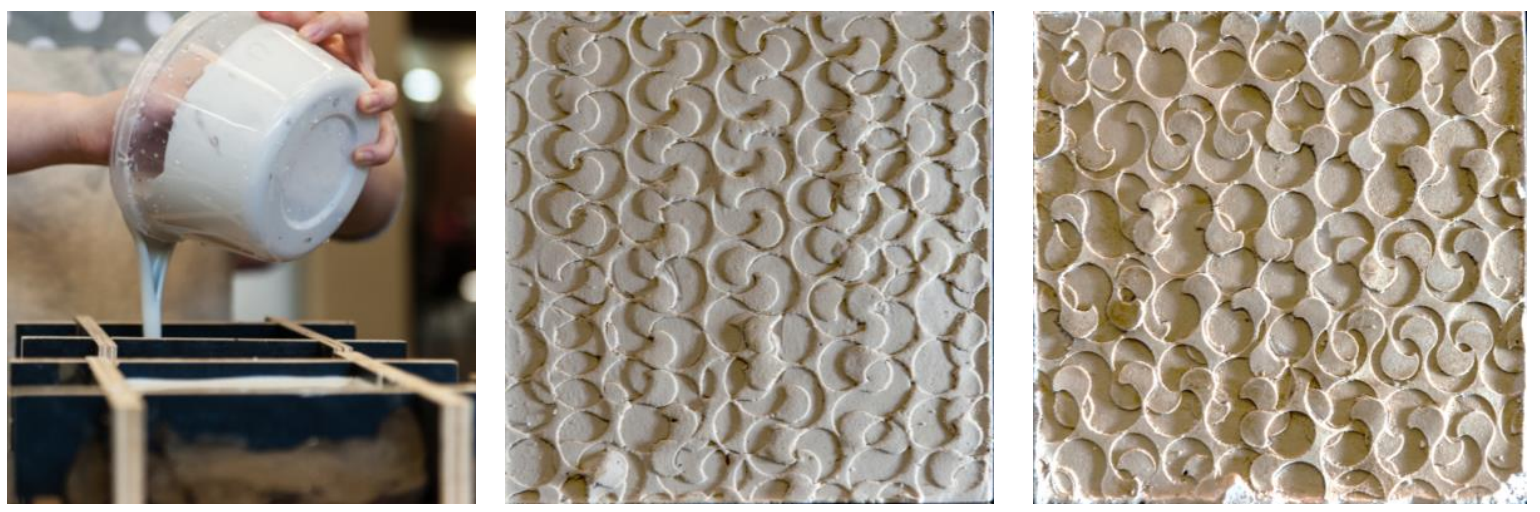

Figure 9. Creation of the plaster moulds and inverted reliefs of plaster moulds.

Those intriguing and astonishing images created by inverted reliefs through manual procedures for the development of design of tiles were described in Bertoldi [2]. Under a closer inspection, the created images are more than their simple mirroring of them because of the lights that reveal the protrusions and depths of the inverted reliefs. On the surface of the clay, the area around the place where an object was pressed has a slight bulge that is perceived only in the demould and this image proves to be interesting to be explored in design.

\subsubsection{Pressing of the newly-created clay recipes in the moulds generated by manual and digital processes}

The clay recipes created in the first day of the workshop were used to be pressed against the plaster moulds made by digital and manual processes with the aim of forming the tiles. Every clay recipe that had been previously prepared could be used to create samples of the ceramic material developed in the workshop. The plaster mould with the created reliefs was pressed against the surface of the clay. After a few minutes, the piece formed was properly encoded and detached from the mould "Fig. 10". Each group of students developed about 12 pieces with different clay recipes and reliefs. 

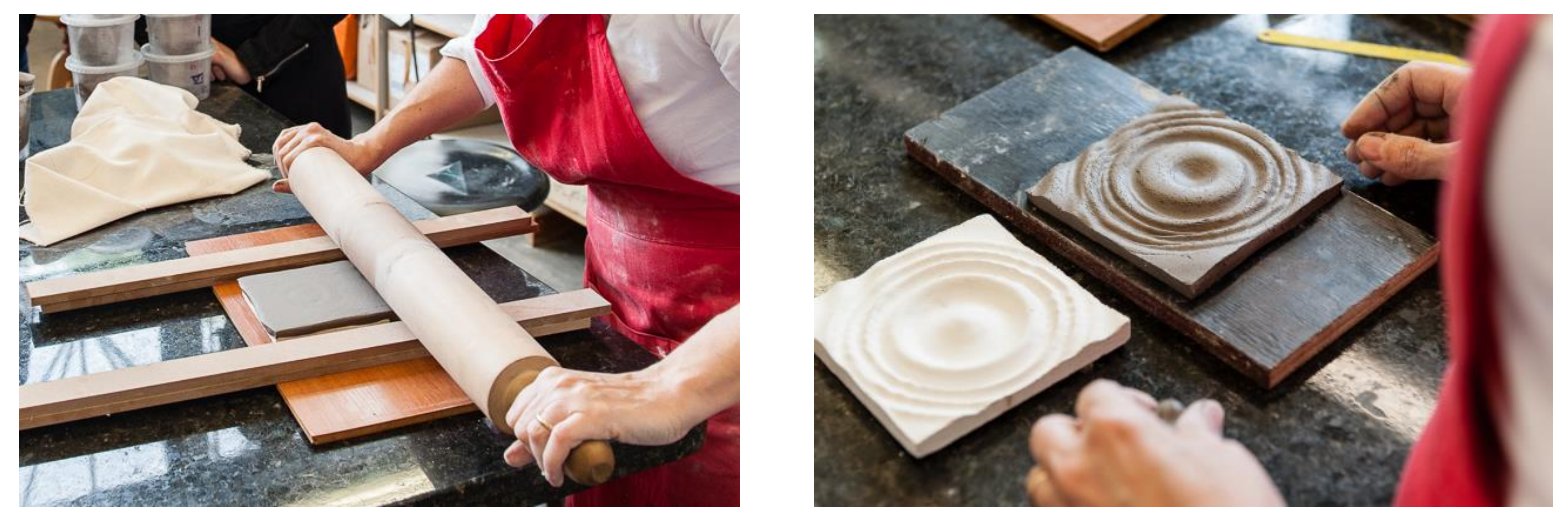

Figure 10. Pressing of the newly-created clay recipes in the moulds and the results.

\subsubsection{Finishing, drying and firing}

The formed prototypes were left to dry and the finishing was made by sanding the edges for burrs removal and correctness of orthogonality. Then, the pieces were fired at $1200^{\circ} \mathrm{C}$ in an electric kiln for $7 \mathrm{~h} 26 \mathrm{~min}$ so as to of obtaining the ceramic materials "Fig. 11".
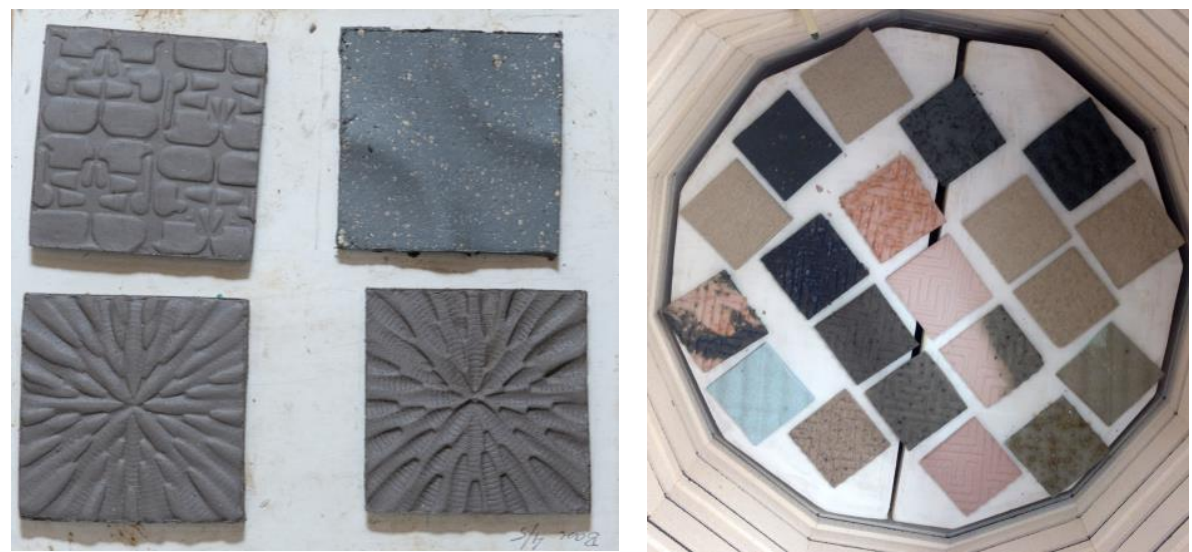

Figure 11. Drying and firing the prototypes at $1200^{\circ} \mathrm{C}$ in an electric kiln

At the end, the opening of the kiln caused a great surprise for the students, mainly concerning the colours and the consistency of materials "Fig 12". Putting all the 85 prototype vertically made them aware that the generation of subtle reliefs and textures is valued when the piece is placed in this way.
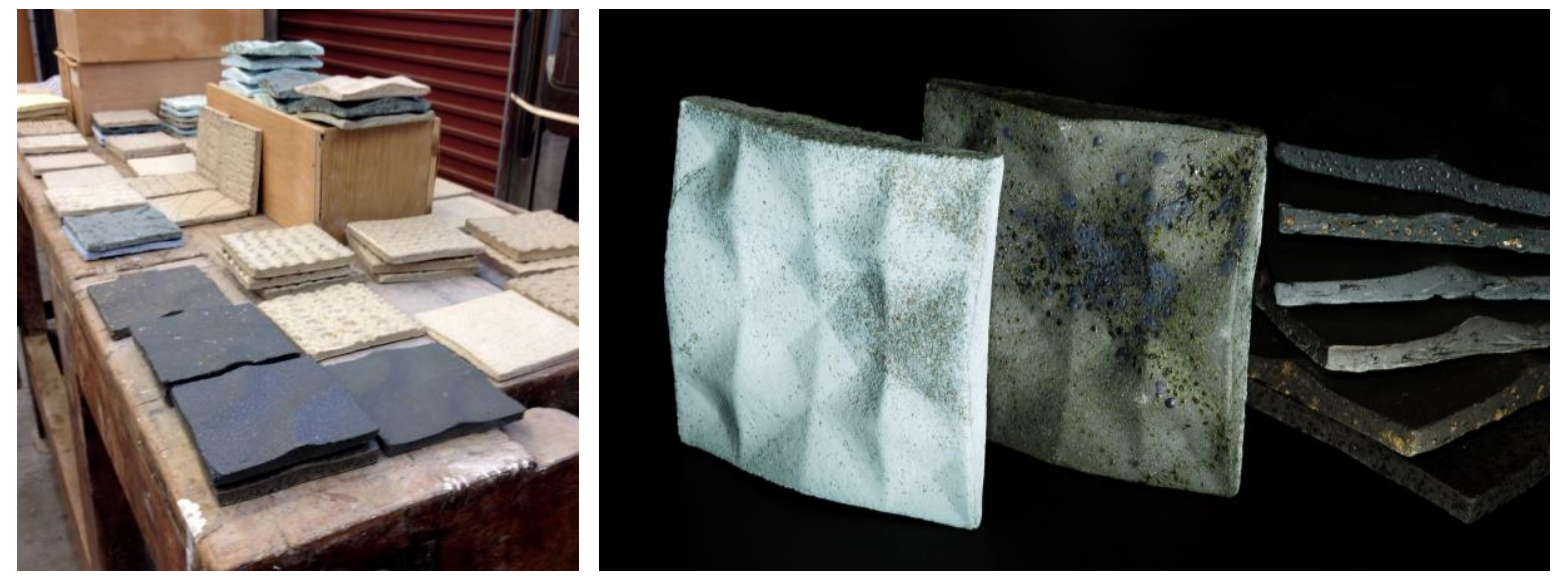

Figure 12. Ceramic prototypes with varied colours, textures and reliefs. 


\section{RESULTS}

\subsection{Evaluation of the workshop and the learning process}

The evaluation of the workshop, in terms of the learning process, was made by the teachers and the students on the last day of the workshop, through a closing debate "Fig. 13". Students were encouraged to express their judgements, critics and recommendations regarding the contents treated, the apprenticeship strategy, the methods used and the activities planned.

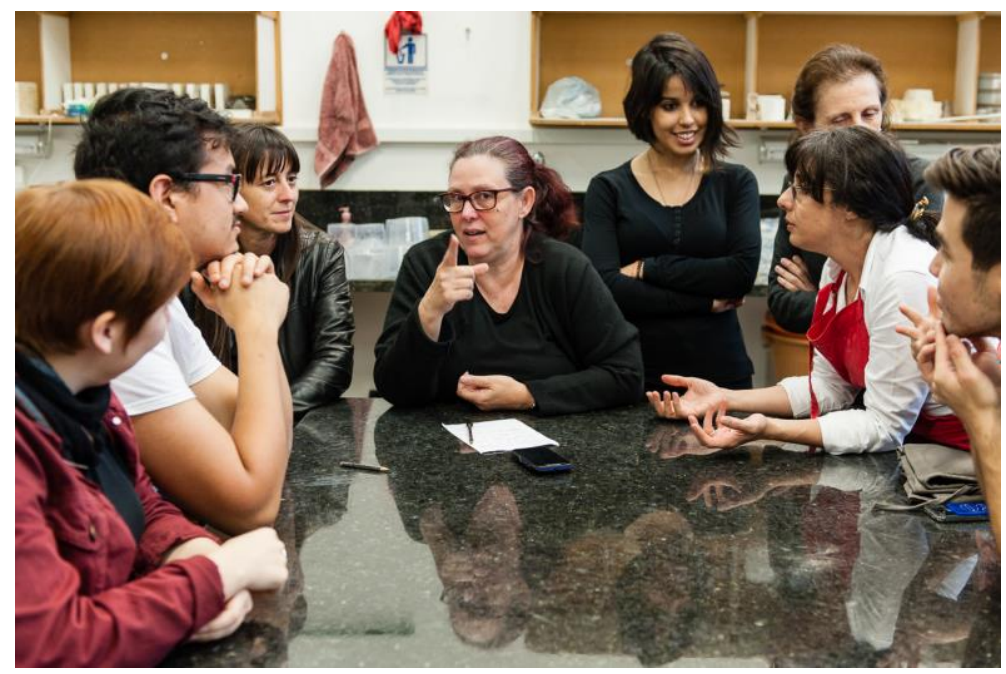

Figure 13. Professors Barbara Del Curto, Denise Dantas and Cristiane Aun Bertoldi and the students gathered to evaluate the workshop.

Students pondered on the potential of learning from experimentation, as well as on the dynamics of the event to understand the content and goals initially outlined. They highlighted the experimentation from the use of the software for the generation of patterns, which enabled a faster verification of the potential of their creations. The use of image processing software for creation and its subsequent conversion into vector images for use in CNC equipment for the generation of the relief was considered very interesting and with potential for other types of application.

The monitoring of the preparation of the machine configurations and the selection of milling tools in relation to the diameter and shape of the miller-cutter, the variation of both the path spacing and the number of paths, showed other possibilities of experimentation in the created patterns during the prototyping phase that can be envisaged in future projects.

Direct experiments with the materials, such as: clay, plaster and ceramic materials were considered by the students as fundamental to grasp their potential for the creation and development of new products. In this sense, using the malleable surface of the clay as a support for the creation, this action worked as a record of the students' first ideas, characterizing itself as an important phase in design. As Tovey emphasized "the first step of the design process to externalise and visualize ideas at an individual level" [3]. As pointed out by Milton \& Rodgers Milton \& Rodgers, [4] "These types of sketches are the initial exploratory visions of how a proposed design may look. They tend to be drawn in a wilfully fluid, dynamic and expressive manner, free from constrains."

After the firing procedure, students could note the influence of oxides, pigments and fillers on changing the colour and the texture of the material. Looking at them, they could also perceive that taking pictures of the prototypes and working with those images to simulate a completed wall, could be the next and interesting step for experimentation and another new and surprising thing should appear.

Moreover, students underlined that the back-and-forth operations from manual to digital processes during the creation and evaluation of ideas and their completion on the materiality of the prototypes enriches the learning process in design and proved to be a fruitful strategy for enlarging their creativity. 


\section{CONCLUSIONS}

The organization of workshops is very effective in promoting the exercise of creative processes. Integrating experimentation and apprehension of new contents, the results obtained in terms of learning surpass what we could call technical apprenticeship on the tried and tested material: ceramics.

Students' final evaluation is fundamental so that they can move from an operational process of doing to a reflexive process, in which they lay out what and how was the experience and they transform it into acquired knowledge capable of being generalized to other future contexts in their professional lives.

Nowadays we live in a digital age so it has become very hard to implement analogical experimentation in the classroom. Students, in general, tend to overestimate digital solutions instead of the manual ones. It is very important to improve the product design student's background so that they have the real dimension of the material world. If they do not know the raw material, they will work to design a new product without a sense of perception of how this product will play its role in everyday tasks. Manzini [5] said that all objects designed by men are the mix between what is thinkable and what is possible to create physically. The intersection of these two points is called "design". Therefore, product design depends on the capacity to predict how materials will behave in that specific shape. In so many classroom digital sketches students forget that these virtual representations are the embryo of their new creation. They do not consider the real material characteristics and it is normal that these creations fail. From the design teaching perspective, it is important that students experience their creation in the real world.

This workshop used ceramic to experiment material but the same structure is possible to apply to any other material. Students were able to compare manual and digital tools to create patterns and visualize the difference between the processes. It was possible to value both methods and understand the main difference between them. From the point of view of teaching, the method used in this workshop has proved to have the potential to be applied to other situations and with other materials in design courses.

\section{ACKNOWLEDGEMENTS}

Photo Credits: @ Ana Paula Maldonado, ( Erika Shiraishi Danielsen, ( C Cristiane Aun Bertoldi

Financial Support:

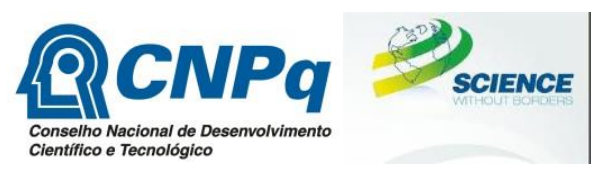

\section{REFERENCES}

[1] N. Grinberg et al., Desenvolvimento de massas cerâmicas com características visuais diversas para utilização em trabalhos artísticos. Final Report. São Paulo: Visual Art Department, Communication and Arts School, University of São Paulo; p.5,3, 2008.

[2] C. A. Bertoldi, Proposta de uma nova linguagem de projeto para o revestimento cerâmico aplicado às fachadas para uso doméstico e/ou comercial. [Thesis]. São Paulo: University of São Paulo, Architecture and Urbanism Faculty; p.125, 2006.

[3] M.Tovey, Design Pedagogy. Developments in Art and Design Education. Surray: Gower Publishing Limited, p.158, 2015.

[4] A. Milton, P. Rodgers, Research methods for product design. London: Laurence King Publishing Ltd, p.34, 2013.

[5] E. Manzini, The material of invention. Cambridge: The MIT Press. p.17, 1993. 